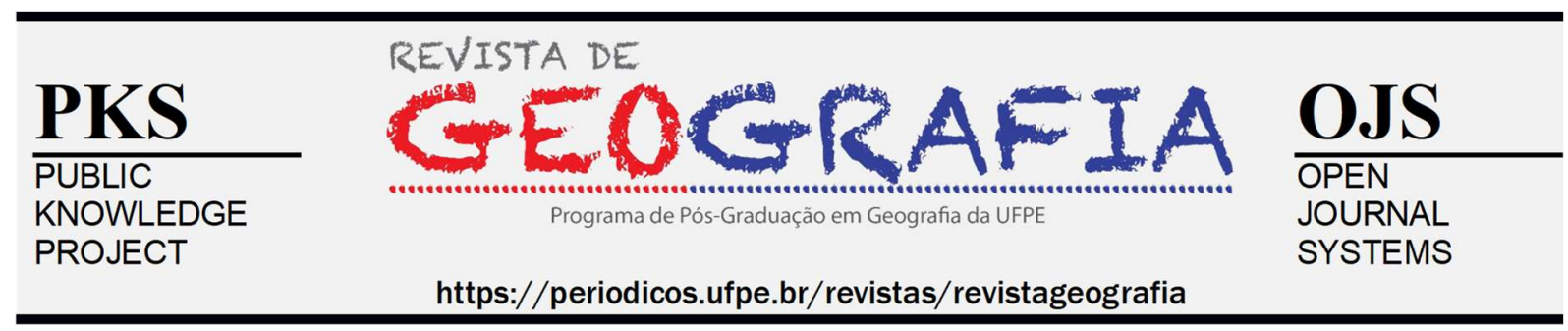

\title{
USO E COBERTURA DO SOLO E COMPARAÇÃO ENTRE OS ÍNDICES DE VEGETAÇÃO SAVI E NDWI NA ÁREA DE PROTEÇÃO AMBIENTAL DAS ONÇAS, PARAÍBA, BRASIL
}

\author{
José Antônio Vilar Pereira ${ }^{1}$, Yuri Gomes de Souza², Iluliane Maria Gadelha Correia ${ }^{3}$, \\ Bartolomeu Israel de Souza ${ }^{4}$
}

\begin{abstract}
${ }^{1}$ Universidade Federal da Paraiba. Mestrando em Geografia. E-mail: joseantoniovilar36@gmail.com
${ }^{2}$ Universidade Federal do Rio Grande do Norte. Mestrando em Geografia.E-mail: yurigomes.s28@gmail.com

${ }^{3}$ Universidade Federal da Paraíba. Mestranda em Geografia. E-mail: iluliane.correia.agro@gmail.com

${ }^{4}$ Universidade Federal da Paraíba. Professor Dr. do Programa de Pós-Graduação em Geografia. E-mail: iluliane.correia.agro@gmail.com
\end{abstract}

Artigo recebido em 11/05/2020 e aceito em 10/06/2020

\begin{abstract}
RESUMO
O Bioma Caatinga apresenta uma biodiversidade exclusiva, porém se encontra em um acelerado processo de modificação das suas paisagens em consequência do uso inadequado dos seus recursos naturais. Entretanto, apesar desse avançado quadro de degradação, apenas algumas das suas áreas são protegidas por unidades de conservação. Desse modo, este trabalho tem como objetivo analisar o uso e a cobertura do solo e entender a influência do relevo nas respostas dos índices de vegetação NDWI e o SAVI na APA das Onças/PB. Nessa direção, analisou-se os índices de vegetação com imagens Sentinel-2 e os dados hipsométricos com imagens do satélite Alos Palsar. Como resultados, identificou-se que a maior parte da área está recoberta por vegetação do tipo Esparsa e Semidensa, compreendendo cerca de 38,9\% e 35,38\% do território da APA, respectivamente, enquanto o Solo Exposto representa 22,07\%, a Vegetação Densa 3,56\% e a Água $0,02 \%$. Com relação às respostas dos índices, estes tiveram resultados aproximados, apresentando uma concentração de valores mais baixos de SAVI e de valores negativos de NDWI na maior parte da APA, indicando áreas degradadas com baixo teor de umidade. Já os valores positivos, estiveram nas zonas mais elevadas, sinalizando presença de vegetação densa e maior umidade.
\end{abstract}

Palavras-chave: Unidade de Conservação; Caatinga; Brejo de Altitude; Geotecnologias.

\section{LAND USE AND COVER AND COMPARISON BETWEEN THE VEGETATION INDICES SAVI AND NDWI ON ENVIRONMENTAL PROTECTION AREA OF THE ONÇAS, PARAÍBA, BRAZIL}

\begin{abstract}
The Caatinga Biome has an exclusive biodiversity, however, has been going through an accelerated process of modifying its landscapes as a result of the inappropriate use of its natural resources. Even with this degradation situation, only some areas are protected by conservation units. This work aims to analyze the land use and cover and understand the influence of the relief on the responses of NDWI and SAVI vegetation indices in APA das Onças/PB. Vegetation indices were analyzed with Sentinel-2 images and hypsometric data with Alos Palsar satellite images. As a result was identified that most of the area is covered by sparse and semi-dense vegetation, comprising about $38.9 \%$ and $35.38 \%$ of the APA territory, respectively, while the Exposed Soil represents 22 , $07 \%$, Dense Vegetation $3.56 \%$ and Water $0.02 \%$. Regarding the indexes responses, these results were approximate, showing a concentration of lower values of SAVI and NDWI values in most of the APA, registering degraded
\end{abstract}


areas with low reading content. The positive values, on the other hand, are in the higher zones, indicating the presence of vegetation and greater density.

Key words: Conservation units; Caatinga; Upland Forest; Geotechnologies.

\section{INTRODUÇÃO}

Inserido no grande grupo das florestas tropicais sazonalmente secas, o bioma Caatinga ocupa a maior parte do Nordeste do Brasil, com predominância na região semiárida, a qual ocupa amplos territórios nos estados do Piauí, Ceará, Rio Grande do Norte, Paraíba, Pernambuco, Alagoas, Sergipe, Bahia, além de uma pequena parte do Maranhão e o norte de Minas Gerais (BRASIL, 2017; DEXTER, et al., 2018; FERNANDES e QUEIROZ, 2018; JATOBÁ, 2019).

O nome Caatinga, dado pelos indígenas, refere-se ao aspecto esbranquiçado que a vegetação adquire quando perde suas folhas nos períodos secos, dominantes ao longo do ano, com pluviosidade média inferior a $800 \mathrm{~mm} /$ ano e temperaturas médias entre 25 e $29^{\circ} \mathrm{C}$. A sua hidrografia é composta predominantemente por rios intermitentes, portanto em grande parte dependente do ritmo das precipitações (AB'SABER, 2003; COUTINHO, 2016).

A Caatinga apresenta grande heterogeneidade florística, sendo formada predominantemente por linhagens antigas que se diversificaram localmente em cada um dos seus núcleos, formando biotas ricas em endemismos e fortemente distintas entre si (FERNANDES e QUEIROZ, 2018). De acordo com os referidos autores, ao contrário das florestas úmidas que tem vastas áreas geográficas cobertas por pouca variedade de espécies de plantas, a Caatinga pode apresentar espécies que são abundantes, porém restritas a determinadas áreas, isto é, cada fragmento do bioma é único e o seu desaparecimento pode sinalizar prejuízos a sua diversidade exclusiva.

Apesar da grande biodiversidade e importância do bioma Caatinga, este vem passando por um drástico processo de modificação das suas paisagens (LEAL, TABARELLI e SILVA, 2003). De acordo com dados do Ministério do Meio Ambiente (MMA, 2009), estima-se que cerca de $80 \%$ dos ecossistemas da Caatinga já tenham sido sujeitados a algum grau de degradação, devido ao uso inadequado dos solos representados principalmente pela pecuária extensiva, agricultura tradicional e uso da vegetação como fonte energética. Essa situação ainda é agravada pelo fato de apenas 7,5\% do bioma atualmente estar sob alguma forma de proteção em unidades de conservação (mais de $98 \%$ na categoria mais branda, Área de Proteção Ambiental - APA), sendo apenas 1,13 \% em área de proteção integral (GARDA et al., 2018). 
As APAs estão previstas na legislação brasileira desde 1981, porém só foram regulamentadas no ano 2000 juntamente com a criação do Sistema Nacional de Unidades de Conservação (SNUC) (SILVA e SOUZA, 2014). Nesse contexto, o objetivo principal das APAs é a conservação dos processos naturais e da biodiversidade, através da orientação, desenvolvimento e adequação das atividades humanas às características naturais do ambiente (GRANJA, 2009).

No estado da Paraíba a maior Unidade de Conservação - UC é a Área de Proteção Ambiental das Onças (APA das Onças). Esta unidade de conservação apresenta áreas com altitudes que podem ultrapassar os 1000 metros, onde segundo Monteiro (2013) a vegetação de Caatinga é dominante, mas também podem ocorrer zonas de transição, como as matas serranas, comumente encontradas na região do Agreste, remanescentes de Mata Atlântica nas áreas de Brejo de Altitude e áreas onde a vegetação tem bastante interferência antrópica, decorrentes principalmente dos usos inadequados do solo e da retirada da vegetação nativa. Portanto, representa um mosaico importante e bastante didático do que se pode encontrar no bioma Caatinga, como poucos até o momento classificados como UCs.

No contexto anteriormente descrito, os Brejos de Altitude funcionam como áreas de exceção dentro do domínio do semiárido brasileiro, se caracterizando como verdadeiras ilhas de florestas úmidas da Mata Atlântica localizados no interior dessa região, cercadas por vegetação de Caatinga (PORTO, CABRAL e TABARELLI, 2004).

Embora possua uma biodiversidade exclusiva, os estudos realizados na Caatinga ainda precisam ser intensificados, entre outros motivos, pelo avançado processo de degradação que o mesmo se encontra. Nessa perspectiva, o uso das Geotecnologias e dos Sistemas de Informações Geográficas (SIG) tem se destacado como importantes ferramentas para realizar tais análises, devido a sua alta capacidade de armazenamento de informações e grande poder de processamento de dados, possibilitando o mapeamento do uso e ocupação do solo, fortalecendo as ações ambientais de monitoramento e agindo como suporte para os instrumentos jurídicos de controle e fiscalização (PEREIRA, BRITO e SOUZA, 2019).

Para obter muitas dessas informações, comumente são utilizados os índices de vegetação, cujo objetivo é extrair e ampliar as informações de vários parâmetros biofísicos incluindo a área foliar, a biomassa, a porcentagem de cobertura do solo, a atividade fotossintética e a produtividade entre outros (PONZONI, 2001). Conforme Silva (2012), estes 
índices são resultantes de operações algébricas entre os valores da reflectância envolvendo duas ou mais faixas espectrais.

Existem diversos índices desenvolvidos com o objetivo de analisar a vegetação de diferentes modos, dentre eles cabe citar o Índice de Vegetação Ajustada ao Solo (SAVI), desenvolvido por Huete (1988) com a finalidade de minimizar as possíveis interferências da energia eletromagnética refletidas pelo solo na área imageada, além de considerar a estrutura dos dosséis e morfologia das plantas (DEMARCHI, PIROLI e ZIMBACK, 2011; PONZONI e SHIMABUKURO, 2007).

Destaca-se também o Índice de Diferença Normalizada da Água (NDWI), proposto por Gao (1996), que busca correlacionar o conteúdo foliar com a água na cobertura vegetal e permite acompanhar mudanças na biomassa e avaliar o estresse hídrico dos bosques vegetacionais.

Diante do exposto, o presente trabalho tem o objetivo de analisar o uso e a cobertura do solo e entender a influência do relevo nas respostas dos índices de vegetação NDWI e o SAVI na Área de Proteção Ambiental das Onças/PB.

\section{MATERIAIS E MÉTODOS}

Área de estudo

A APA das Onças é a maior unidade de conservação do estado da Paraíba, compreendendo uma extensão de $36.000 \mathrm{~km}^{2}$. Localiza-se no município de São João do Tigre, na mesorregião da Borborema e na microrregião do Cariri Oriental (Figura 1).

O clima da APA das Onças está inserido na classe BSwh' (seco de tipo xerófito) da classificação de Köppen, com temperatura média de $18{ }^{\circ} \mathrm{C}$. O regime de chuvas na APA é complexo, pois uma parte, mais próximo da área urbana do município de São João do Tigre, tem médias de precipitação de $600 \mathrm{~mm}$, enquanto outras áreas tem médias de precipitação que ultrapassam os 800 mm (MONTEIRO, 2013; LIMA, 2014), sendo nessas últimas onde podese encontrar alguns remanescentes "ilhados" de Mata Atlântica. 


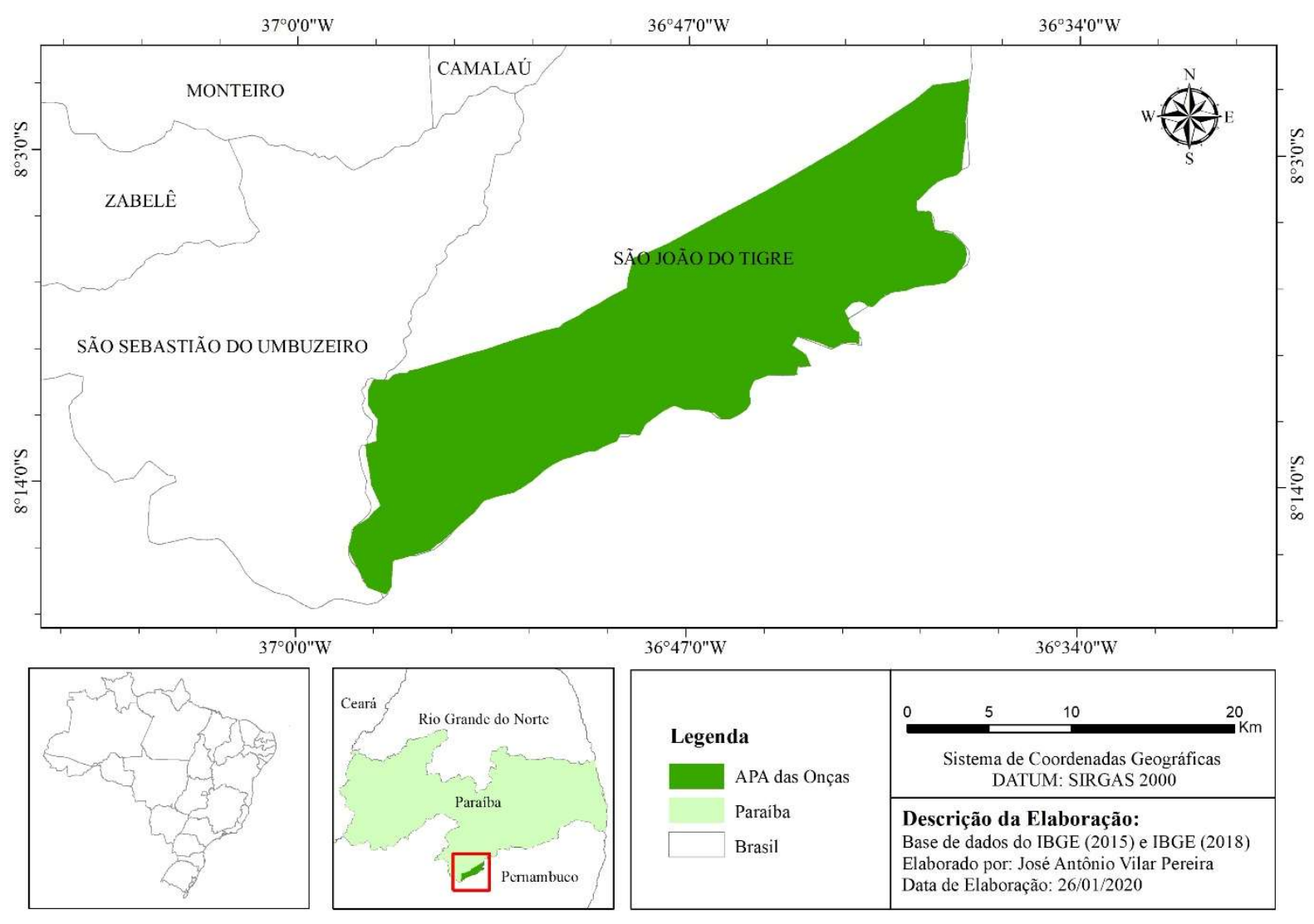

Figura 1. Localização da Área de Proteção Ambiental das Onças/PB. Fonte: Autores, 2020.

\section{Procedimentos Metodológicos}

Com base nos objetivos propostos, o trabalho foi desenvolvido obedecendo as seguintes etapas: 1) Aquisição das imagens de satélite; 2) Pré-processamento e 3) Processamento Digital das Imagens-PDI. Para a realização do PDI e elaboração dos mapas temáticos foram utilizados os softwares QGIS 3.4.10 e o ArcGIS 10.5. Para os demais procedimentos foi utilizado o Google Earth Pro.

\section{Aquisição das imagens}

O mapa hipsométrico foi elaborado a partir de imagens do satélite ALOS Palsar da Japan Aerospace Exploration Agency - (JAXA). Foram obtidas duas imagens deste satélite, disponibilizados gratuitamente a partir do geoportal da Alaska Satellite Facility da NASA. Vale ressaltar que essas imagens são geradas através da reamostragem do Modelo Digital de Elevação (MDE) do radar SRTM (Shuttle Radar Topography Mission) que originalmente apresenta resolução espacial de 30 metros, resultando em um produto com resolução de 12,5 metros (TAROLLI e MUDD, 2019; ASF, 2020). 
Para o mapeamento do uso e ocupação do solo e o cálculo dos índices de vegetação na APA foram utilizadas duas imagens do satélite Sentinel-2 captada pelo sensor MSI (Multi Spectral Instrument) ambas correspondentes à data 06/05/2019, especificamente as imagens das bandas 4 e 8 com resolução espacial de $10 \mathrm{~m}$ e as bandas $8 \mathrm{~A}$ e 11 com resolução espacial de 20 m. Tais cenas foram obtidas gratuitamente através do site Glovis do Serviço de Geologia dos Estados Unidos (USGS). Optou-se pelo uso dessas imagens devido à baixa porcentagem de nuvens detectadas para essa data e principalmente pelo fato de, sendo período chuvoso na região, poder melhor identificar as áreas que não respondem positivamente mesmo submetidas à presença de água, caracterizando-se como degradadas, onde a vegetação é escassa ou rarefeita.

\section{Pré-Processamento}

Mosaico e recorte das imagens (Alos Palsar e Sentinel-2)

A área de estudo está localizada entre dois pontos orbitais da faixa de imageamento do satélite Sentinel-2, desse modo foi necessário utilizar duas imagens que compreendessem a área total da APA. O mesmo ocorreu com as imagens do satélite Alos Palsar. Sendo assim, foi preciso, para ambos, realizar o mosaico das imagens através da ferramenta Image Analysis do software ArcGIS 10.5. Este procedimento, segundo Bagli e Fonseca (2005), consiste em unir duas ou mais imagens para se obter uma nova imagem com área maior.

Posteriormente realizou-se o recorte do mosaico para facilitar o processamento dos dados. Tal procedimento foi efetuado através da ferramenta Extract by Mask do software ArcGIS 10.5 utilizando a delimitação da área de estudo em formato shapefile.

\section{Correção atmosférica (BOA) (Sentinel-2)}

As imagens do Sentinel-2 são disponibilizadas originalmente com Correção da Reflectância no Topo da Atmosfera (Top Of Atmosphere - TOA), sendo necessário para a geração de índices de vegetação a conversão para Correção da Reflectância na Base da Atmosfera (Bottom Of Atmosphere Reflectance ou BOA). Essa etapa foi efetuada no software QGis 3.4, através do método Dark Object Subtraction 1 (DOS1) das 12 bandas do satélite Sentinel-2 através da ferramenta Processing na aba Conversion. 


\section{Processamento Digital das Imagens (PDI)}

Imagens Alos Palsar:

O processamento das imagens Alos Palsar foi efetuado no software ArcGIS 10.5, consistindo na elaboração do mapa de hipsometria, descrito a seguir:

\section{Hipsometria}

Elaborada a partir da opção Classified, a qual permite inserir valores de equidistância entre as cotas altimétricas que foram divididas em cinco classes com valores que variaram entre 679 a $1168 \mathrm{~m}$.

\section{Imagens Sentinel - 2}

Para o Sentinel-2, o PDI consistiu no cálculo dos Índices de Vegetação Ajustado ao Solo (SAVI) e do Índice de Diferença Normalizada da Água (NDWI), realizado também no software ArcGIS 10.5:

\section{SAVI (Índice de Vegetação Ajustado ao Solo)}

Esse índice tem o intuito de diminuir a influência da resposta espectral do solo mediante a inclusão de um fator de ajuste (L) que é variável com o grau de recobrimento do dossel das plantas (PONZONI e SHIMABUKURO, 2007). Conforme os autores supracitados, o fator de ajuste do SAVI foi obtido de forma que o índice resultante tivesse o mesmo valor para vegetação, independente se o solo fosse claro ou escuro. Esse pode variar no valor do L, onde 0 é utilizado para coberturas vegetais mais densas a 1 para vegetação menos densa. $\mathrm{O}$ valor utilizado neste trabalho foi 0,5 o que corresponde a uma densidade vegetal intermediária. O SAVI é calculado através da equação (1) proposta por Huete (1988):

$$
S A V I=\frac{(1+L) * \rho i v-\rho v}{L+\rho i v+\rho v}
$$

Onde: L é o fator de ajuste, piv é a banda do infravermelho e $\rho v$ a banda do vermelho.

\section{Classificação}

Após o cálculo do SAVI, realizou-se a classificação não supervisionada para a confecção do mapa de uso e cobertura do solo. Esse tipo de classificação examina os dados e 
os divide em agrupamentos espectrais naturais predominantes presentes na imagem através de uma variedade de algoritmos (LIMA, 2014). Optou-se pelo uso desse tipo de classificação, devido a extensão da APA e pela melhor diferenciação das classes de vegetação. Dessa forma, foram obtidas as seguintes classes de uso e ocupação do solo: Vegetação Densa, Vegetação Semidensa, Vegetação Esparsa, Solo Exposto e Água.

Para diferenciação das classes de uso e ocupação do solo no mapeamento, adaptou-se para área de estudo os critérios estabelecidos nos trabalhos de Souza, Suertegaray e Lima (2011) e de Lima e Almeida (2017), descritos a seguir:

- Vegetação Densa: vegetação com boas condições de conservação, geralmente encontrada nas áreas de maior altitude e com baixa presença de atividades antrópicas, podendo também aparecer nas margens dos rios e nas áreas de solos mais desenvolvidos. Normalmente, a vegetação dessas áreas é composta pelos extratos arbóreo e arbustivo fechado.

- Vegetação Semidensa: essa classe representa uma transição entre a categoria anterior e uma vegetação mais esparsa, com a presença de algumas áreas de solos desnudos. Predominam nesse grupo, plantas do extrato arbustivo e herbáceo.

- Vegetação Esparsa: nessa categoria está a vegetação com avançado processo de degradação, presente, geralmente nas áreas mais planas do relevo e com bastante atividades antrópicas. Apresenta grandes manchas de solos expostos e uma vegetação com plantas muito dispersas, com a presença predominante do extrato herbáceo e algumas plantas do extrato arbustivo isoladas.

- Solo Exposto: áreas totalmente degradadas, sem a presença de vegetação e/ou de afloramentos rochosos.

- Água: reservatórios artificiais de água.

A quantificação das classes foi realizada por meio da análise do histograma da imagem. Cada pixel da imagem Sentinel-2 tem a dimensão de 10mx10m, desse modo é possível obter a área em metros quadrados de cada classe de uso e ocupação, multiplicando-se o valor total dos pixels por classe pelo tamanho da área de um pixel $\left(100 \mathrm{~m}^{2}\right)$. 
$N D W I$

O Índice de Diferença Normalizada da Água foi projetado com a finalidade de determinar o limiar entre água, vegetação e solo (BRENNER e GUASSELLI, 2015). Com isso, segundo McFeeters (1996) e Gao (1996), o cálculo deste índice expressa-se a partir da equação (2):

$$
\mathrm{NDWI}=(N I R-S W I R) /(N I R+S W I R)
$$

Onde, NIR é a banda do infravermelho próximo (banda 8); e SWIR é a banda vermelho (banda 11).

\section{Dados de precipitação}

As precipitações do semiárido brasileiro se caracterizam pela grande irregularidade, tanto espacial, como temporalmente. Tais peculiaridades se refletem na resposta espectral da vegetação da Caatinga. Nesse contexto, segundo Oliveira et al. (2010), a maioria das espécies perdem suas folhas na longa estação seca, diminuindo deste modo a sua biomassa, o que pode ser confundido no mapeamento como áreas de Solo Exposto, quando na realidade se trata de um processo natural. Dessa forma, a precipitação é uma variável importante a ser observada antes de analisar as repostas dos índices de vegetação.

Levando em consideração essa especificidade, os dados de precipitação utilizados nesta pesquisa para a elaboração das médias mensais do ano de 2019 foram adquiridos através do site institucional da Agência Executiva de Gestão das Águas do Estado da Paraíba (AESA).

\section{RESULTADOS E DISCUSSÕES}

Uso e ocupação do solo

Ao realizar a classificação dos parâmetros espectrais da imagem do satélite Sentinel 2, foram identificadas seis classes principais de uso e ocupação do solo: Vegetação Esparsa, Vegetação Semidensa, Vegetação Densa, Solo Exposto e Água. A espacialização das classes mapeadas pode ser observada na figura 2. 


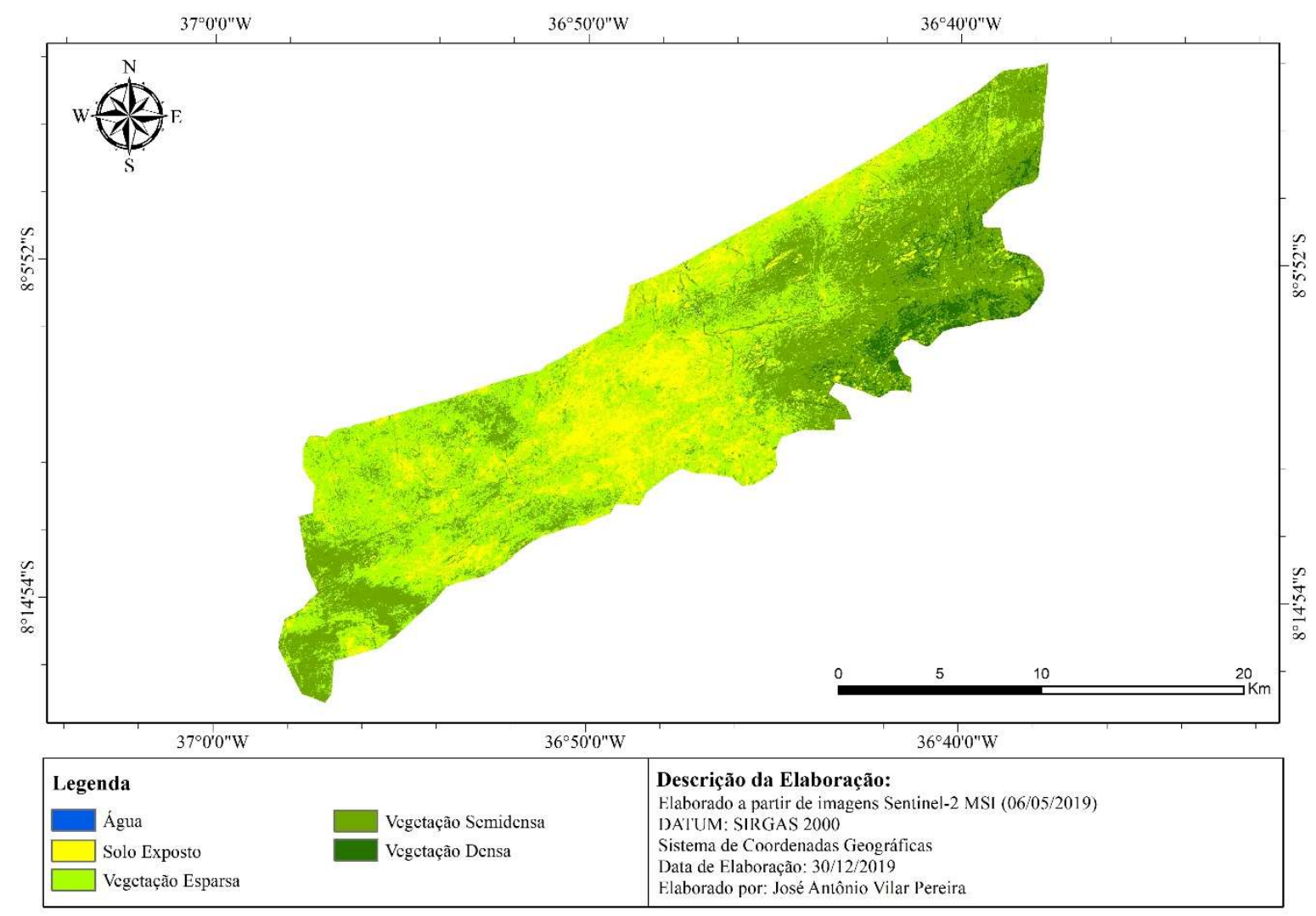

Figura 2. Uso e cobertura do solo na APA das Onças/PB. Fonte: Autores, 2020.

Com base na figura 02, observamos que as áreas com maior cobertura vegetal (Vegetação Densa) estão concentradas em remanescentes localizados na parte sudeste da APA, onde também temos grandes áreas de Vegetação Semidensa, presentes da mesma forma em concentrações relativamente altas na parte sudoeste, enquanto as outras classes encontram-se espalhadas pelo restante da área de estudo, havendo uma presença perceptivelmente destacada de Solo Exposto na parte central dessa UC. Em termos quantitativos, os resultados podem ser observados na tabela 01 , apresentada abaixo:

\begin{tabular}{l|c|c}
\multicolumn{1}{c|}{ Classes } & $\mathbf{K m}^{\mathbf{2}}$ & $\mathbf{\%}$ \\
\hline Água & 0,08 & 0,02 \\
\hline Solo Exposto & 85,06 & 22,07 \\
\hline Vegetação Esparsa & 150,19 & 38,97 \\
\hline Vegetação Semidensa & 136,34 & 35,38 \\
\hline Vegetação Densa & 13,73 & 3,56 \\
\hline \multicolumn{1}{c}{ Total } & 385,4 & 100 \\
\hline
\end{tabular}

$\overline{\text { Tabela 1. Classes de uso e ocupação do solo. Fonte: Autores, } 2020 .}$ 
De acordo com os dados expostos na tabela 1, percebemos que a Vegetação Esparsa foi a classe de maior representação na APA, com $150,19 \mathrm{~km}^{2}$, o que em porcentagem equivale a $38,97 \%$ da área total. A classe identificada como Vegetação Semidensa contabilizou 136,34 $\mathrm{km}^{2}(35,38 \%)$, seguida pela classe solo Exposto com 85,06 km² (22,07\%). As categorias de uso do solo que ocuparam as menores áreas foram a Vegetação Densa, com 13,73 km² (3,56\%), e a Água, com apenas $0,08 \mathrm{~km}^{2}(0,02 \%)$.

Os resultados obtidos denotam uma estreita relação com a questão do relevo na APA das Onças, em particular o fator altitude, apresentado a seguir (Figura 3), em sua influência nas condições de chuva e temperatura e também no que diz respeito ao favorecimento ou desfavorecimento quanto ao uso e ocupação dos solos e aproveitamento dos recursos naturais, em particular a vegetação.

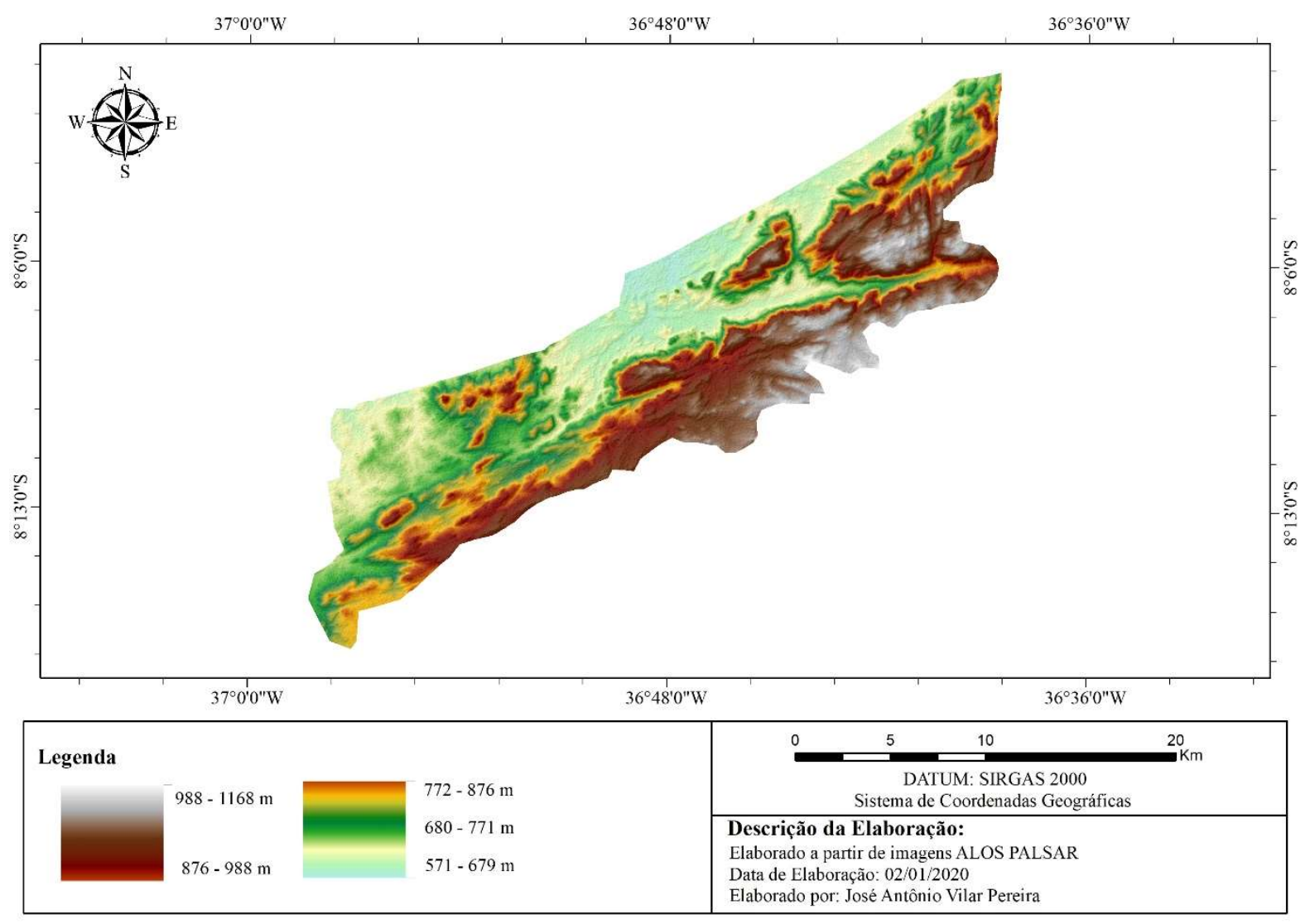

Figura 3. Hipsometria da APA das Onças/PB. Fonte: Autores, 2020.

Ao compararmos os mapas de uso e ocupação do solo (Figura 2) com o mapa de hipsometria (Figura 3), pode ser observado que as áreas de vegetação mais preservada, 
classificadas no mapeamento como Vegetação Densa e Vegetação Semidensa predominam nas áreas de maior altitude, com cotas de hipsometria acima dos $800 \mathrm{~m}$. Já nas áreas com maiores níveis de degradação, referentes a Vegetação Esparsa e Solo Exposto, estão localizadas na porção mais central e a leste da área de estudo, nas zonas de relevo com altitudes inferiores a $600 \mathrm{~m}$.

Nessa perspectiva, podemos perceber que o relevo e particularmente o fator topográfico tem influência direta nas especificidades ambientais da APA, uma vez que nessas áreas há uma maior dificuldade para o desenvolvimento de atividades e ocupação humana, significando, portanto, na maior conservação de seus padrões vegetacionais. Entretanto, nos trechos de menores altitudes e topografia menos acidentada, onde ocorre maior predominância de ações antrópicas, é possível verificar maiores níveis de degradação da vegetação.

Segundo Monteiro (2013), a disposição do relevo em relação às massas de ar, também tem importante papel na determinação das paisagens encontradas na APA. Desse modo, conforme a autora, nas regiões à barlavento das zonas serranas, onde podem ser encontradas melhores condições de precipitação e de umidade, predomina uma vegetação mais densa a semidensa, enquanto nas áreas a sotavento e com clima semiárido, predomina uma vegetação de Caatinga Hipoxerófila e Hiperxerófila mais esparsa.

Os resultados obtidos nessa UC são corroborados em áreas similares do bioma Caatinga. Por exemplo, Araújo, Queiroz e Lopes (2019), ao estudarem a composição e estrutura da vegetação do Brejo de Altitude da Serra dos Cavalos, no estado de Pernambuco, verificaram que ocorrem mudanças vegetacionais de densidade ao longo dos níveis topográficos. Segundo os autores referidos, as frequentes perturbações antrópicas, localizadas nas áreas de menor altitude, representam os maiores índices de fragmentação e de baixa densidade vegetacional nestas áreas.

Ainda nessa linha de raciocínio, Nóbrega et al. (2019), ao analisarem a inter-relação do relevo e do clima em Pernambuco, verificaram que estes possuem grande influência sobre a dinâmica das paisagens vegetais. A depender do arranjo espacial dos fatores climáticos, estes atuam de maneira a aumentar ou reduzir a disponibilidade hídrica, o que implicará em modificações fisiográficas da vegetação ao longo de um transecto que perpassa áreas próximas com patamares distintos de relevo, vindo assim a corroborar que a interação dos elementos atmosféricos com o relevo ocorre de modo distinto, culminando em uma expressiva variedade vegetal de paisagens úmidas, subúmidas e semiáridas. 
Comparação entre os índices de vegetação SAVI e NDWI

Ao analisarmos a espacialização dos índices de vegetação na figura 4, observa-se que o SAVI apresentou resultados semelhantes ao NDWI para a mesma data de captura da imagem de satélite. Desse modo, houve uma concentração de valores mais baixos em grande parte da APA para ambos os índices, indicando uma predominância de áreas degradadas com baixo teor de umidade na vegetação.

Com relação ao SAVI, foi possível observar uma concentração de valores entre (-0,155 e 0,290) nas terras com maior desenvolvimento de atividades humanas e portanto, com paisagens mais degradadas, como nas áreas de solo exposto e de vegetação mais rarefeita, representadas no mapeamento pelas cores vermelho, amarelo e laranja. O mesmo ocorreu com os resultados do NDWI que indicou vastas extensões da APA com valores negativos (-0,624 a -0,05), ou seja, uma baixa presença de umidade na vegetação nas mesmas áreas onde o SAVI indicou uma vegetação com menor vigor vegetativo.

À medida que nos aproximamos das regiões de maior altitude do relevo, onde é possível encontrar uma vegetação mais preservada, foi registrado uma concentração de valores maiores de SAVI (0,291 a 0,730). Mais uma vez, essa resposta apresentou correlação com a espacialização do NDWI que apresentou valores entre 0,06 e 0,61 nas mesmas áreas. Tais resultados, portanto, corroboram o que já foi dito sobre a influência do relevo na cobertura vegetal e nos padrões de uso e cobertura do solo. 


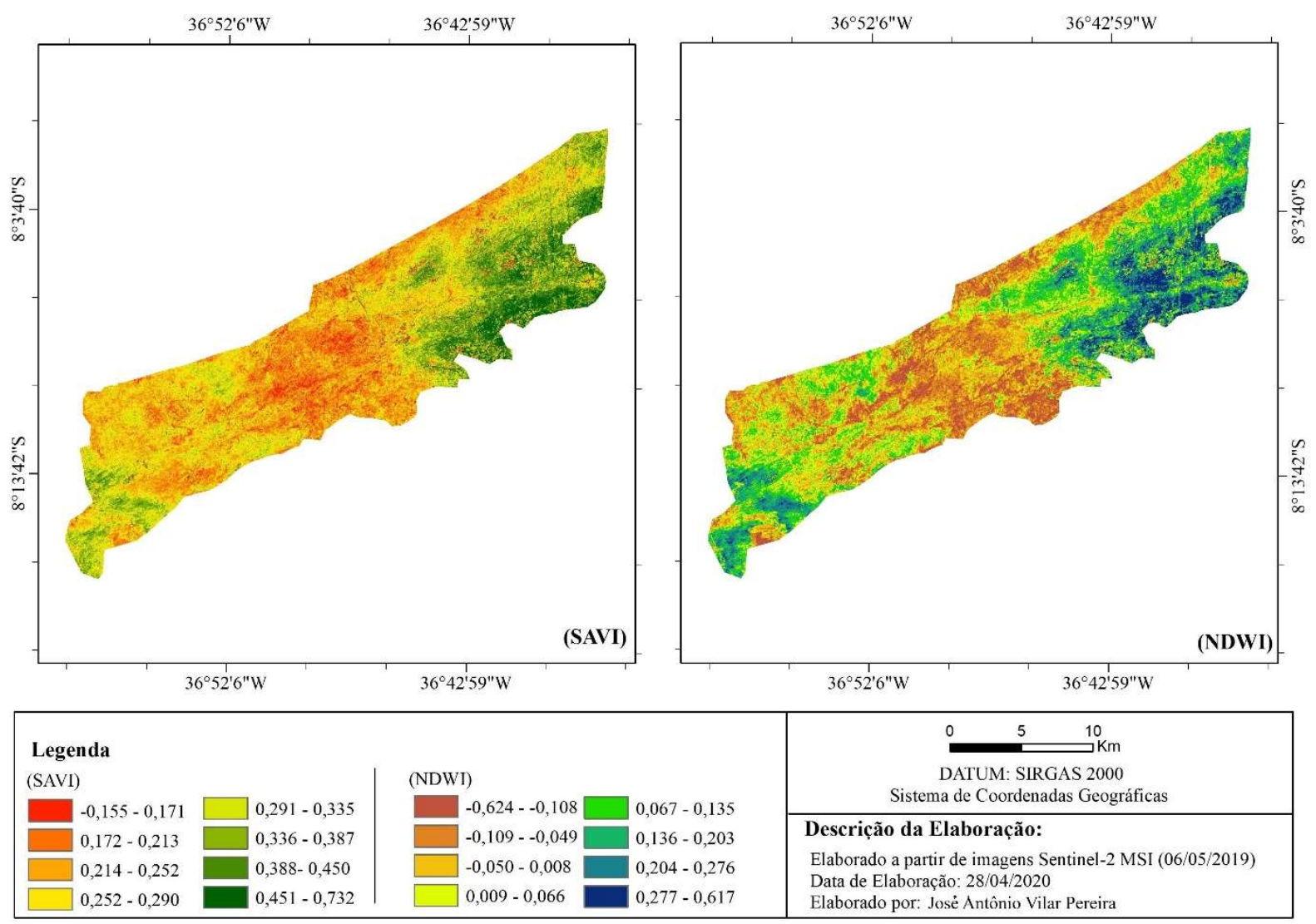

Figura 4. Comparação entre o SAVI e o NDWI. Fonte: Autores, 2020.

Com base na comparação do comportamento dos índices, pode-se observar na figura 5 que a resposta do SAVI acompanha a do NDWI, demonstrando, dessa forma, as mesmas características de vegetação na área de estudo. Ou seja, nos setores onde os menores valores de SAVI indicaram uma vegetação com maior grau de degradação, o NDWI indicou uma menor presença de umidade, enquanto que nos trechos onde foram registrados maiores valores de SAVI, correspondendo a uma vegetação com maior presença de biomassa, a resposta do NDWI indicou uma maior concentração de umidade. 


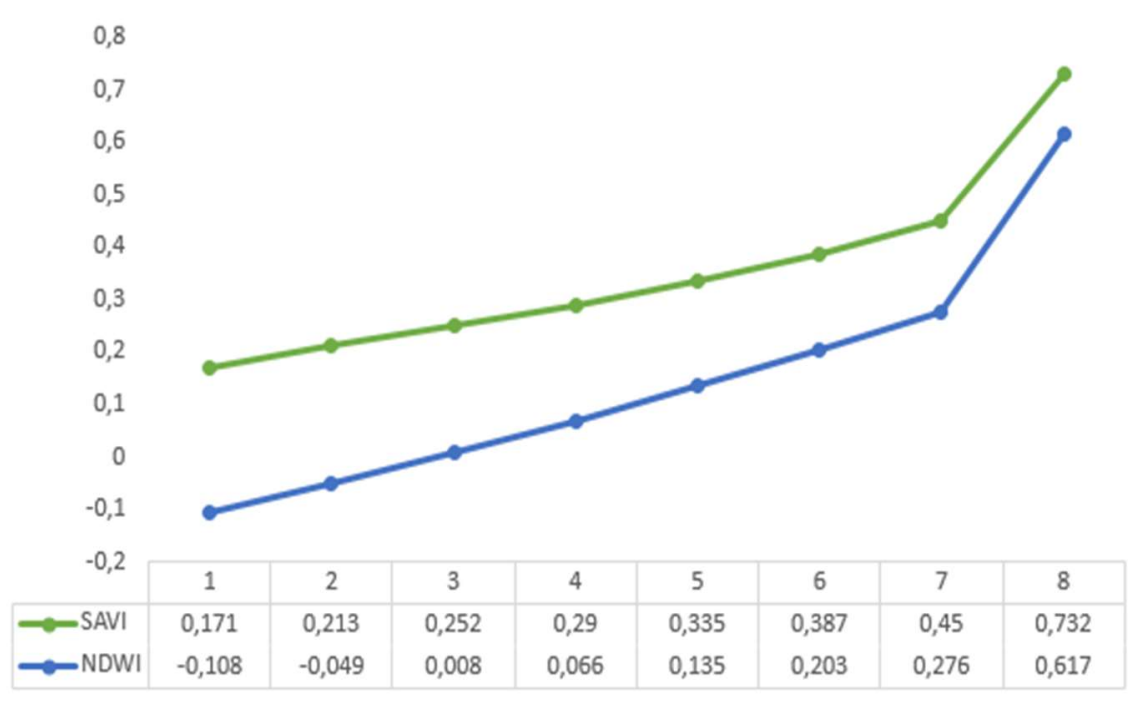

Figura 5. Comparação entre as respostas do SAVI e do NDWI. Fonte: Autores, 2020.

Vale ressaltar que o SAVI varia de -1 a 1 , onde valores negativos indicam a presença de corpos d'água, valores mais próximos a 0 indicam áreas de solo exposto, nuvem e/ou vegetação muito rarefeita e valores mais próximos a 1, correspondem a uma vegetação mais densa. O NDWI também varia de -1 a 1, porém conforme Serrano, Shahidian e Silva (2019), para a vegetação seca ou com menor presença de umidade, os valores são mais próximos de números negativos, enquanto os valores positivos, mais próximos de 1, referem-se a vegetação verde e com maior teor de umidade.

Como já nos reportamos anteriormente, a vegetação da Caatinga é bastante sensível às variações de precipitação, com a maioria das espécies perdendo todas as suas folhas na estação seca e recuperando-as rapidamente quando começa o período chuvoso. Portanto, a variável precipitação é de extrema importância para entendermos a resposta dos índices de vegetação. Nesse contexto, são apresentadas na figura 6, a seguir, as médias mensais de precipitação na área de estudo no ano de 2019. 


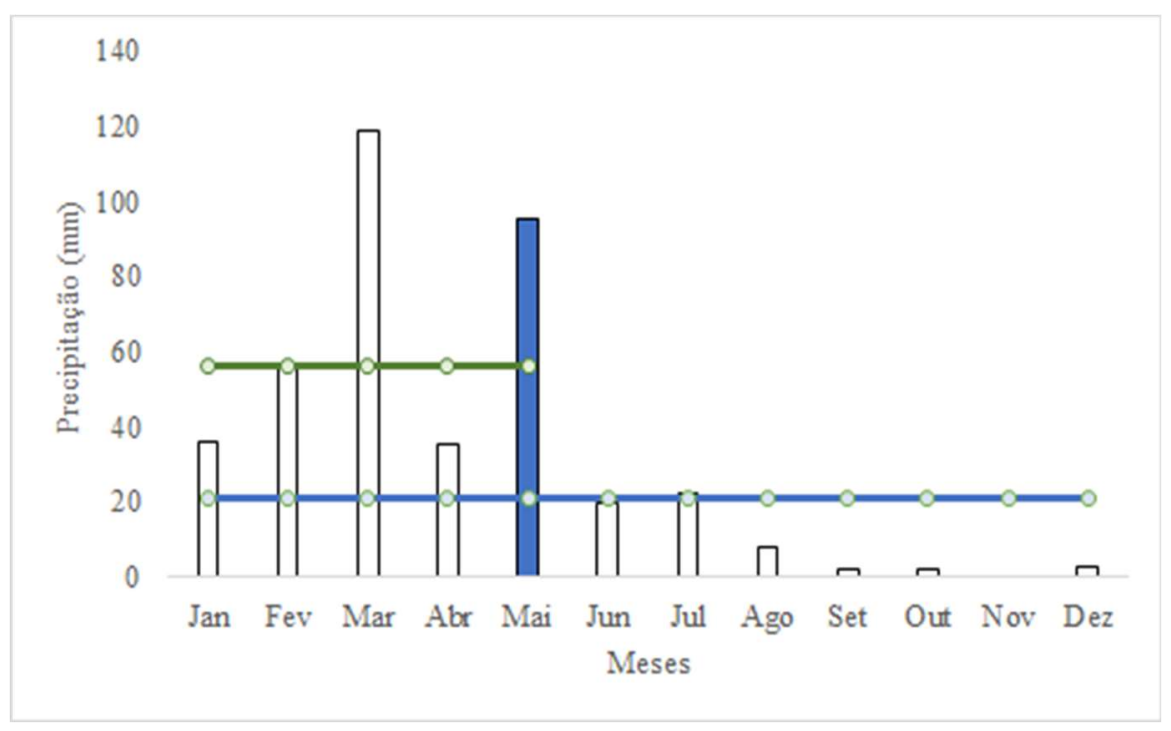

Figura 6. Pluviometria anual do município de São João do Tigre/PB 2019. A linha de cor verde corresponde a média dos meses mais chuvosos, a em azul, a média anual de precipitação; a coluna em cor azul, o mês para o qual foram analisadas as imagens de satélite neste trabalho. Fonte: AESA (2019).

Com base nos resultados expostos na figura 6 , nota-se que de janeiro a maio foram registrados consideráveis volumes de precipitação, onde a média para esses cinco primeiros meses $(56,1 \mathrm{~mm})$ foi superior à média anual $(21,3 \mathrm{~mm})$. Neste período, destacam-se os meses de março, com média de 118,7 mm, e maio, com 95,2 mm, sendo este último, conforme já informado, correspondente ao mês de captura da imagem.

Nessa perspectiva, os dados pluviométricos sinalizam respostas ambientais importantes frente aos resultados do SAVI e do NDWI, uma vez que a distribuição da precipitação nos primeiros meses do ano de 2019 contribuiu para a manutenção da cobertura foliar da vegetação, sendo quantitativamente mais expressivos nas áreas de relevo mais alto e melhor preservadas da APA.

Assim, justifica-se também os valores negativos encontrados, visto que, mesmo com os altos índices de precipitação, as áreas degradadas apresentaram valores de umidade inferiores, indicando a presença de áreas de solo exposto e/ou vegetação rarefeita compondo ambientes que, nem sob a presença de chuva, conseguem recuperar uma cobertura vegetal, ao menos mais adensada, demonstrando que o nível de resiliência dessas áreas, frente aos impactos provocados pelas atividades humanas, foi ultrapassado, constituindo-se como espaços de difícil recuperação espontânea, o que também pode ser observado em outras áreas do bioma Caatinga. 
No contexto anteriormente destacado, Ferreira et al. (2012), ao analisarem a dinâmica da vegetação no município de Petrolina/PE através de índices de vegetação NDWI e NDVI, associados a temperatura da superfície e dados climatológicos, identificaram que a resposta da vegetação da Caatinga variou de acordo com a ocorrência de precipitação, apresentando no período chuvoso valores mais elevados de índice de vegetação e temperaturas menores, enquanto no período mais seco ocorreram baixos valores dos índices e altas temperaturas.

Souza, Macêdo e Silva (2015) analisando as temperaturas dos solos na região dos Cariris Velhos paraibanos (na qual a APA das Onças está inserida), para identificar a relação com o processo de germinação de sementes de espécies da Caatinga, observaram que no período entre os anos de 1987 a 2011, as temperaturas médias dos solos da região aumentaram, atualmente sendo registrado valores superiores aos $35^{\circ} \mathrm{C}$, em consequência principalmente da retirada da cobertura vegetal e da expansão das áreas de solo exposto.

Nesse contexto, os autores concluíram que poucas são as sementes de espécies da Caatinga que conseguem germinar nessa média de temperatura. Portanto, o processo de recuperação dessas áreas que têm um elevado índice de degradação e desertificação através dos processos de sucessão ecológica é bastante difícil, mesmo que fosse cessado o uso constante aos quais são submetidas.

Em síntese, comparando-se os mapas de uso e ocupação do solo, hipsometria e umidade, fica evidente a associação entre essas três características na APA, como pode ser observado na figura 7 , abaixo. 


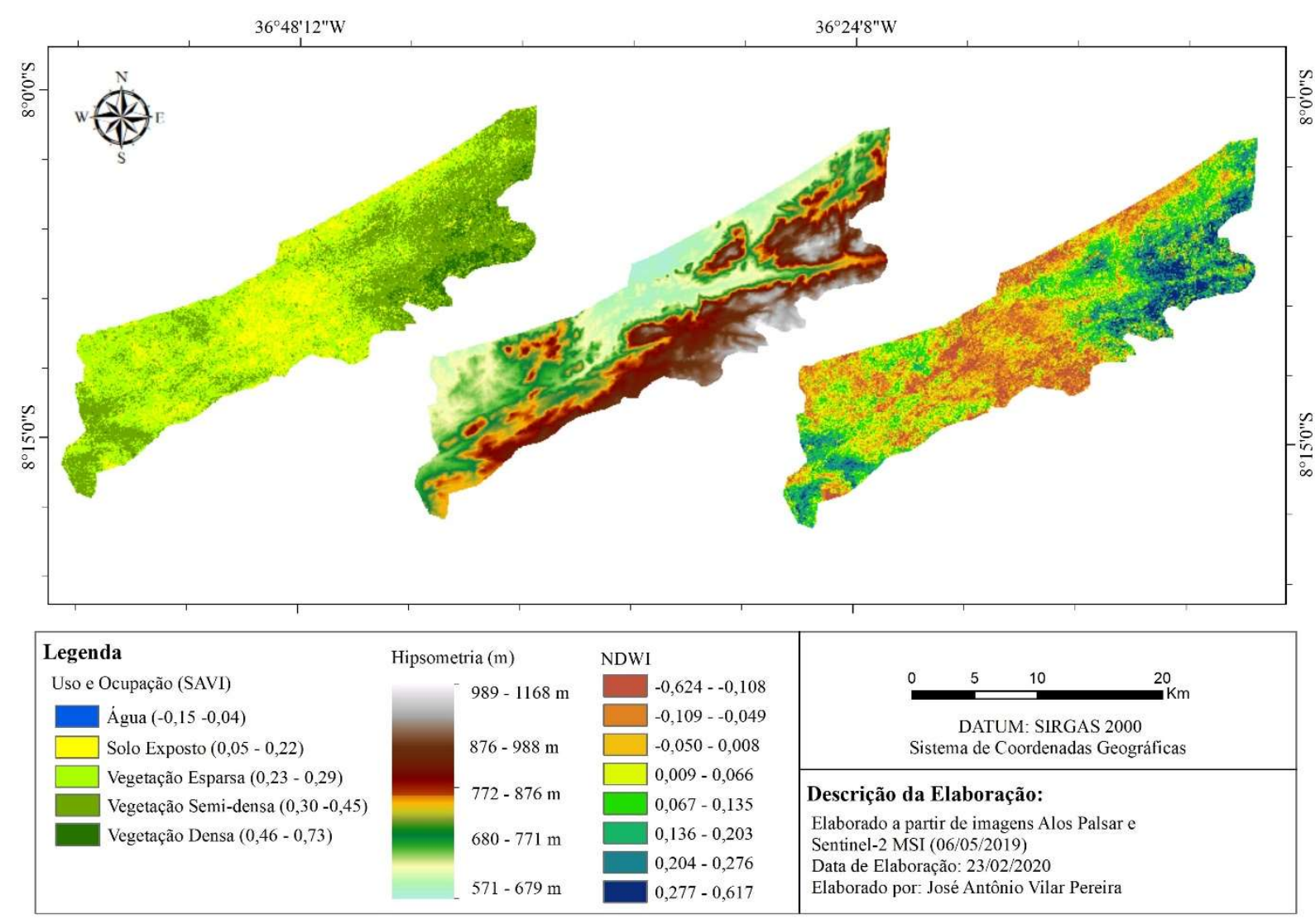

Figura 7. Comparação entre as características de uso e ocupação do solo, hipsometria e umidade. Fonte: Autores, 2020.

Portanto, os resultados apresentados mostram uma relação direta entre relevo, distribuição das massas de ar, cobertura vegetal (em termos de densidade e diversidade) e interferência humana nessa UC, obedecendo a um padrão observado para toda essa região no trabalho de Souza, Suertegaray e Lima (2011).

\section{CONSIDERAÇÕES FINAIS}

Diante dos resultados encontrados, pôde-se observar que os fatores topográficos relacionados aos climáticos influenciam diretamente na distribuição e na densidade da cobertura vegetal da APA. Nesse sentido, foi possível constatar respostas aproximadas entre os índices SAVI e NDWI que indicaram uma concentração de áreas degradadas com baixo teor de umidade nas porções mais planas do relevo. Por outro lado, os maiores valores, encontrados nas terras mais elevadas, sinalizaram a ocorrência de coberturas vegetais mais densas.

Para além disso, os resultados também indicam a fragilidade deste tipo de unidade de conservação frente aos mais variados processos de degradação, expressos pelo domínio das 
classes Solo Exposto e Vegetação Esparsa, uma vez que não se cumpre efetivamente com o uso sustentável dos recursos naturais aí existentes, denotando falta de fiscalização e de apoio governamental às comunidades humanas locais para o desenvolvimento de ações de fato sustentáveis.

Portanto, baseado nessas considerações, é importante salientar a necessidade de implementação de um manejo mais efetivo ou a troca da categoria de unidade de conservação do tipo uso sustentável para outra que garanta a conservação mais eficiente desse ambiente, particularmente pela variedade de paisagens encontradas nessa UC, o que lhe confere um patrimônio ambiental de grande riqueza, particularmente o fato de ser uma das poucas áreas do Cariri paraibano onde temos a presença de Brejos de Altitude, zonas fundamentais para a dinâmica hídrica do semiárido brasileiro.

\section{REFERÊNCIAS BIBLIOGRÁFICAS}

ARAÚJO, T. G.; QUEIROZ, A. B.; LOPES, S. F. Fitossociologia de um brejo de altitude no semiárido brasileiro: variação das espécies dominantes ao longo do gradiente altitudinal. Ciência Florestal, v. 29, n. 2, p. 779-794, 2019.

AB'SÁBER, A. N. Os domínios da natureza no Brasil: potencialidades paisagísticas. São Paulo: Ateliê Editorial, 2003.

ASF - Alaska Satellite Facility, 2015. ASF Radiometric terrain corrected products. Disponível em: https://asf.alaska.edu. Acesso em: 02 de jun. de 2020.

BAGLI, V. V.; FONSECA, L. M. G. Mosaico de Imagens baseado na Análise em Múltiplas Resoluções. Anais... VII Simpósio Brasileiro de Geoinformática, Campos do Jordão, Brasil, 20-23 nov. 2005, INPE, p. 236-244.

BRASIL. Superintendência do Desenvolvimento do Nordeste - SUDENE, 2017. Estados e municípios. Disponível em: http://www.sudene.gov.br/area-de-atuacao/estados-e-municipios Acesso em: set. 2019.

COUTINHO, L. M. Biomas brasileiros. São Paulo: Oficina de Textos, 2016.

DEMARCHI, J. C.; PIROLI, E. L.; ZIMBACK, C. R. L. Análise temporal do uso do solo e comparação entre os índices de vegetação NDVI e SAVI no município de Santa Cruz do Rio Pardo - SP usando imagens LANDSAT-5. RAEGA, v. 21, p. 234-271, 2011. 
DEXTER, K.G; PENNINGTON, R. T; OLIVEIRA FILHO, A. T; BUENO, M. L; SILVA, M. P. L; NEVES D. M. Inserting Tropical Dry Forests Into the Discussion on Biome Transitions in the Tropics. Frontiers in Ecology and Evolution, vol. 6, 104 p., 2018.

FERNANDES, M. F.; QUEIROZ, L. P. Vegetação e flora da Caatinga. Ciência e cultura, v. 70, n. 4, p. 51-56, 2018.

FERREIRA, J. M. S. et al. Análise Espaço-Temporal da Dinâmica da Vegetação de Caatinga no Município de Petrolina-PE. Revista Brasileira de Geografia Física, v. 5, n. 4, p. 904-922, 2012.

GARDA, A. A. et al. Os animais vertebrados do Bioma Caatinga. Ciência e Cultura, v. 70, n. 4, p. 29-34, 2018.

GAO, B. C. NDWI - A Normalized difference water index for remote sensing of vegetation liquid water from space. Remote sensing of environment, v. 58, n. 3, p. 257-266, 1996.

GRANJA, L. V. A. C. O papel das áreas de proteção ambiental: APA’s na conservação dos recursos naturais em áreas urbanas. 2009. 208 f. Dissertação (Mestrado) - Curso de Programa de Pós Graduação em Arquitetura e Urbanismo, UNB, Brasília, 2009.

HUETE, A.R. A soil-adjusted vegetation index (SAVI). Remote Sensing of Environment, v.25, p.295-309, 1988.

JATOBÁ, L. Elementos de climatologia e geomorfologia do trópico Semiárido Brasileiro. Recife: Profciamb, 2019, 48 p.

LIMA, F. S; ALMEIDA, N. V. Dinâmica espaço-temporal da cobertura vegetal na Área de Proteção Ambiental (APA) do Cariri, Paraíba-PB, Brasil. Revista Brasileira de Geografia Física, v. 10, n. 03, p. 699-721, 2017.

LEAL, I.R.; TABARELLI, M.; SILVA, J.M.C. Ecologia e conservação da caatinga. Recife: Ed. Universitária da UFPE, 2003.

LIMA, M. N. S. Classificação ecodinâmica das unidades de paisagem na área de preservação ambiental das onças, no município de São João do Tigre/PB. 2014. 136 f. Dissertação (Mestrado em Geografia) - Universidade Federal da Paraíba, João Pessoa, 2014.

MMA - Ministério do Meio Ambiente, 2009. Caatinga: Contexto, Características e Estratégias de Conservação. Disponível em: https://www.mma.gov.br. Acesso em: 06 de mar. de 2020.

MONTEIRO, T. R. R. Uso dos Solos, Índice de Vegetação e Degradação na APA das OnçasPB. 2013. 106 f. Dissertação (Mestrado) - Curso de Programa de Pós Graduação em Geografia, UFPB, João Pessoa, 2013. 
NÓBREGA, R.S; SANTIAGO, G. A. C. F; SOARES, D. B. Tendências do controle climático oceânico sob a variabilidade temporal da precipitação no Nordeste do Brasil. Revista de geografía Norte Grande, n. 63, p. 9-26, 2016.

OLIVEIRA, T. H.; MACHADO, C.C.C.; SILVA, J.S.; GALVÍNCIO, J.D.; PIMENTEL, R.M.M.; SILVA, B.B. Índice de Umidade (NDWI) e Análise Espaço-Temporal do Albedo da Superfície da Bacia Hidrográfica do Rio Moxotó-PE. Revista Brasileira de Geografia Física, V. 3, n. 2, p. 55-69, 2010.

PEREIRA, J. A. V.; BRITO, E. F.; SOUZA, Y. G. Análise Espaço-Temporal do Uso da Superfície no Parque Nacional da Serra da Capivara/PI a Partir do Sensoriamento Remoto. Espaço Aberto, PPGG - UFRJ, Rio de Janeiro, v. 9, n.1, p. 129-142, 2019.

PONZONI, F. J. Comportamento Espectral da Vegetação. In: MENESES, P. R., NETTO, J. S. M. (Org.) Sensoriamento remoto, reflectância dos alvos naturais. Brasília: Ed. Universidade de Brasília - UNB, Embrapa Cerrados, p. 157-199, 2001.

PONZONI, F. J.; SHIMABUKURO, Y. E. Sensoriamento remoto no estudo da vegetação. São José dos Campos: Parêntese, 2007. 136p.

PORTO, K. C.; CABRAL, J. J. P.; TABARELLI, M. Brejos de altitude em Pernambuco e Paraíba: história natural, ecologia e conservação. Brasília: Ministério do Meio Ambiente, 2004. 324p.

SERRANO, J; SHAHIDIAN, S; SILVA, J. M. Evaluation of Normalized Difference Water Index as a Tool for Monitoring Pasture Seasonal and Inter-Annual Variability in a Mediterranean Agro-Silvo-Pastoral System. Water, v. 11, n. 1, p. 62-82, 2019.

SILVA, J. B. Sensoriamento Remoto aplicado ao estudo do ecossistema manguezal. Tese se Doutorado, Universidade Federal de Pernambuco, UFPE, Brasil, 2012. 188p.

SILVA, E. A. L.; SOUZA, B. I. Percepção das Problemáticas Socioambientais: estudo de caso da Área de Proteção Ambiental das Onças, São João do Tigre, Paraíba. In: Anais... IV Congresso Nordestino de Biólogos, João Pessoa, Paraíba, 2014.

SOUZA, B. I.; MACÊDO, M. L. A; SILVA, G. J. F. Temperatura dos solos e suas influências na regeneração natural da Caatinga nos Cariris Velhos - PB. Raega, v. 35, p. 261-287, 2015. SOUZA, B. I.; SUERTEGARAY, D. M. A.; LIMA, E. R. V. Evolução da desertificação no Cariri paraibano a partir da análise das modificações na vegetação. Rio Claro: Revista Geografia, v. 36, n. 1, p. 193-207, 2011.

TAROLLI, P; MUDD, S. M. Remote Sensing of Geomorphology. Elsevier, 2019. 